\title{
CXCL1 expression is correlated with Snail expression and affects the prognosis of patients with gastric cancer
}

\author{
ZHEN XIANG $^{1 *}$, DA-PING JIANG ${ }^{2 *}$, GUANG-GAI XIA $^{1 *}$, ZHE-WEI WEI $^{1}$, WEI CHEN $^{1}$, \\ ${\text { YULONG } \mathrm{HE}^{1} \text { and CHANG-HUA ZHANG }}^{1}$ \\ ${ }^{1}$ Department of Gastrointestinopancreatic Surgery, The First Affiliated Hospital of Sun Yat-Sen University, Guangzhou, \\ Guangdong 510080; ${ }^{2}$ Department of Surgery, The First Affiliated Hospital of Wannan Medical College, \\ Wuhu, Anhui 241000, P.R. China
}

Received October 6, 2014; Accepted July 9, 2015

DOI: $10.3892 / 01.2015 .3614$

\begin{abstract}
Gastric cancer (GC) continues to result in a poor survival rate and prognostic biomarkers for the disease are lacking. Chemokine (C-X-C motif) ligand (CXCL1) expression plays a critical role in tumor metastasis, and Snail promotes epithelial-mesenchymal transition (EMT) to promote metastasis. Therefore, the present study aimed to investigate the correlation between CXCL1 and Snail expression and the effect of CXCL1 expression on the survival of patients with GC. CXCL1 and Snail expression in paraffin-embedded tissue sections from 127 patients with GC were each assessed by immunohistochemistry. Cox regression and Kaplan-Meier analyses were performed to evaluate the prognostic significance of CXCL1 and Snail. Evaluation of the association between CXCL1 and Snail expression and clinical characteristics was based on the $\chi^{2}$ test. Spearman's rank correlation coefficient and Fisher's exact test were used to explore the association between CXCL1 and Snail expression in GC tissues. CXCL1 was found to be significantly associated with tumor invasion $(\mathrm{P}=0.003)$, tumor-node-metastasis $(\mathrm{TNM})$ staging $(\mathrm{P}=0.001)$, tumor size $(\mathrm{P}=0.013)$ and lymph node metastasis $(\mathrm{P}=0.022)$ in $\mathrm{GC}$. Snail overexpression was also significantly associated with tumor invasion $(\mathrm{P}=0.001)$, TNM staging $(\mathrm{P}=0.005)$, tumor size $(\mathrm{P}=0.026)$, lymph node metastases $(\mathrm{P}=0.014)$ and perineural invasion $(\mathrm{P}=0.009)$. CXCL1 and Snail expression were independent factors for a worse overall survival rate, as determined by multivariate analysis $(\mathrm{P}=0.011$ and $\mathrm{P}=0.018$; respectively). The combined expression of CXCL1 and Snail resulted in a worse prognosis compared with the other three groups $(\mathrm{P}=0.005)$.
\end{abstract}

Correspondence to: Professor Chang-Hua Zhang, Department of Gastrointestinopancreatic Surgery, The First Affiliated Hospital of Sun Yat-Sen University, 58 Zhongshan 2nd Road, Guangzhou, Guangdong 510080, P.R. China

E-mail: zhchangh@mail.sysu.edu.cn

*Contributed equally

Key words: CXCL1, Snail, gastric cancer, overall survival, prognosis
Furthermore, there was a significantly positive correlation between CXCL1 and Snail expression in GC $(\mathrm{r}=0.431 ; \mathrm{P}<0.001)$. The expression of CXCL1 is significantly associated with Snail expression and may be used as a predictive co-biomarker for patient prognosis and tumor aggressiveness in GC. CXCL1 may promote GC metastasis by regulating EMT.

\section{Introduction}

Gastric cancer (GC) is the fourth most common type of cancer and the second leading cause of cancer-associated mortality worldwide (1). Metastasis remains the major cause of mortality in patients with GC, despite advancements in the understanding and treatment of cancer $(2,3)$. Therefore, exploring the molecular mechanisms underlying GC metastasis may provide novel insights into tumor treatment and predicting patient prognosis. Chemokine (C-X-C motif) ligand 1 (CXCL1), also termed GRO-1 oncogene, is a member of the $\mathrm{G}$ protein-coupled receptor family that binds specifically to $\mathrm{CXC}$ chemokine receptor 2 (CXCR2) (4). CXCL1 is overexpressed in melanoma tumors and is involved in malignant transformation (5). In addition, CXCL1 activates nuclear factor (NF)- $\kappa \mathrm{B}$ signaling through epidermal growth factor receptor-transactivated Akt and contributes to CXCR2-mediated ovarian cancer progression (6). CXCL1 was also found to contribute to prostate tumor cell migration and invasion through the activation of NF- $\mathrm{B}(7)$. In GC, overexpression of CXCL1 and its receptor CXCR2 were found to be associated with tumor metastasis and a poor prognosis (8). However, the role of CXCL1 as a prognostic biomarker and the mechanism in tumor metastasis remain unknown. Epithelial mesenchymal transition(EMT) is a process that results in epithelial cells losing intercellular adhesion and obtaining myofibroblastic features and is critical for tumor invasion and metastasis (9). Snail is a zinc-finger transcription factor that may promote EMT, and overexpression of Snail is associated with lymph node metastasis and a poor prognosis in patients with GC $(10,11)$. In GC, NF- $\kappa$ B activation by tumor necrosis factor-Z, cyclooxygenase- 2 and Rho guanosine diphosphate-dissociation inhibitor 2 increase Snail expression, and Snail downregulates E-cadherin and promotes EMT (12-14).

In the present study, the prognosis value of the expression of CXCL1 and Snail was investigated and the correlation 
between CXCL1 and Snail expression was evaluated. The current study aimed to identify a prognostic biomarker in GC and suggest a possible mechanism for the effect of CXCL1 in tumor metastasis.

\section{Materials and methods}

Patients and samples. In total, 127 patients with GC that underwent radical resection at the Department of Gastrointestinopancreatic Surgery of the First Affiliated Hospital of Sun Yat-Sen University (Guangzhou, Guangdong, China) between 2005 and 2007 were enrolled in the present study. The staging of the resected specimens was performed using the tumor-node-metastasis (TNM) classification of malignant tumors established by the International Union Against Cancer (15). No patients received adjuvant therapy, such as radiotherapy, chemoradiotherapy or chemotherapy, or other medical interventions. The present study was approved by the Research Ethics Committee of Sun Yat-Sen University. Prior to enrollment in the present study, written informed consent was obtained from all patients.

Immunohistochemistry. Tissue specimens were fixed in $10 \%$ neutral buffered formaldehyde and were embedded in paraffin. All samples were histologically reviewed by hematoxylin and eosin staining. Tissue sections were cut into $4-\mu \mathrm{m}$ thick slices and slides were coated with 3-aminopropyltriethoxysilane (Guangzhou Xiuwei Commerce Co., Ltd., Guangzhou, China). Mouse anti-human CXCL1 monoclonal antibody (dilution, 1:50; catalog no., MAB275; R\&D Systems, Inc., Minneapolis, MN, USA) and rabbit anti-human Snail monoclonal antibody (dilution, 1:50; catalog no., ab180714; Abcam, Cambridge, UK) were used. The slides containing paraffin-embedded tissue sections were baked at $65^{\circ} \mathrm{C}$ for $2 \mathrm{~h}$, deparaffinized in xylene (3 times for $10 \mathrm{~min}$ each) and then rehydrated in ethanol (100, 95 and $75 \%$ graded series). Subsequently, the sections were autoclaved at $121^{\circ} \mathrm{C}$ for $8 \mathrm{~min}$ in citrate buffer $(10 \mathrm{mmol} / \mathrm{l}$ sodium citrate; $\mathrm{pH}$ 6.0) for antigen retrieval. Endogenous peroxidase activity was blocked by incubating the slides in $0.3 \% \mathrm{H}_{2} \mathrm{O}_{2}$ solution. The sections were blocked with normal goat serum to block non-specific binding and then incubated with the aforementioned rabbit anti-Snail and mouse anti-CXCL1 antibodies overnight at $4^{\circ} \mathrm{C}$. Subsequently, secondary antibody (goat anti-rabbit/mouse antibody; 1:100 dilution; cat no. CW2069A; CWBio, Beijing, China) was incubated with the tissue sections for $20 \mathrm{~min}$. Finally, the slides were counterstained with hematoxylin (Loogene Biotechnology Co., Ltd., Beijing, China), dehydrated with ethanol, permeabilized with dimethylbenzene and mounted for assessment.

Evaluation of immunohistochemical variables. Two independent observers, who were blinded to the clinical outcomes of the cases, performed the immunohistochemical analysis (16). Subsequent to counting 1,000 tumor cells (high-power field, $\mathrm{x} 400$ ), the percentage of cancer cells with Snail-positive nuclei was recorded. Nuclear expression of Snail was graded by classifying the extent of positive nuclear staining as $\leq 10,11-25$, 26-50, 51-75 and $>75 \%$. The H-scoring system was used for semi-quantitative analysis of CXCL1 expression in the GC tissue specimens (17).
Statistical analysis. Actuarial OS rates were calculated using the Kaplan-Meier method and differences between the survival curves were analyzed using the log-rank test. The survival time was recorded in days and was defined as the time between the surgical procedure and mortality or the last review. Univariate and multivariate analyses based on the Cox proportional hazards regression model were used to determine the association between the survival time and multiple clinicopathological variables. In order to compare the individual variables, the $\chi^{2}$ test was performed. Spearman's rank correlation coefficient and Fisher's exact test were used to explore the association between CXCL1 and Snail expression. $\mathrm{P}<0.05$ was considered to indicate a statistically significant difference. All analyses were performed using SPSS 19.0 software (IBM, Armonk, NY, USA).

\section{Results}

Patient characteristics. The clinicopathological characteristics of all patients are summarized in Table I. The patients consisted of 92 males and 35 females. The median age was 57 (26-87) years old. The mean follow-up time of the patients was $42.3 \pm 2.6$ months.

Expression of CXCL1 and Snail in GC tissues. The expression levels of CXCL1 and Snail in tumor and para-carcinoma tissues obtained from patients with GC were examined by immunohistochemical analysis. Figs. 1 and 2 revealed the expression of CXCL1 and Snail in the para-carcinoma tissue of patients with GC. Fig. 1B and E exhibits the staining of CXCL1 and Snail in the tumor tissue of patients with GC. Fig. 1C and F is representative of strong staining for CXCL1 and Snail in the tumor tissue of patients with GC. The dark brown immunostaining was frequently observed in tumor cells, whereas extremely few incidences of brown staining appeared in the para-carcinoma tissue of patients with GC. A receiver operating characteristic curve was used to determine the cut-off value for CXCL1 and Snail-positive cases. The cut-off value for tissue specimens with CXCL1 scores is $>97.2 \%$, thus, scores of $\leq 97.2 \%$ indicated no expression; this resulted in $62.2 \%$ patients being defined as expressing CXCL1, while the remaining patients $(37.8 \%)$ had scores that resulted in the tissue being classified as not expressing CXCL1. Positive nuclear staining for Snail at levels of $\leq 75 \%(55.9 \%)$ and $>75 \%(44.1 \%)$ was defined as demonstrating the absence and presence of Snail expression, respectively.

CXCL1 and Snail expression was associated with overall survival in GC. Cox regression and Kaplan-Meier analysis were performed to evaluate the prognostic effects of low or high expression of CXCL1 and Snail in GC tissue specimens. Univariate analysis revealed that neither patient age nor patient gender demonstrated any prognostic significance for the OS rate of patients with GC. However, the tumor size $(\mathrm{P}<0.001)$, presence of lymph node metastasis $(\mathrm{P}<0.001)$, TNM staging $(\mathrm{P}<0.001)$, depth of tumor infiltration $(\mathrm{P}<0.001)$, presence of distant metastasis $(\mathrm{P}<0.001)$ and development of peritoneal dissemination $(\mathrm{P}=0.001)$ were significantly associated with the OS rate (Table II). The overexpression of CXCL1 $(\mathrm{P}<0.001)$ 
Table I. Clinicopathological characteristics of 127 patients with gastric cancer.

\begin{tabular}{|c|c|}
\hline Characteristic & Total, $\mathrm{n}(\%)$ \\
\hline \multicolumn{2}{|l|}{ Gender } \\
\hline Male & $92(72.4)$ \\
\hline Female & $35(27.6)$ \\
\hline \multicolumn{2}{|l|}{ Age } \\
\hline$<60$ years & $77(60.6)$ \\
\hline$\geq 60$ years & $50(39.4)$ \\
\hline \multicolumn{2}{|l|}{ Location } \\
\hline Upper third & $42(33.1)$ \\
\hline Middle third & $28(22.0)$ \\
\hline Lower third & $46(36.2)$ \\
\hline Whole & $11(8.7)$ \\
\hline \multicolumn{2}{|c|}{ Tumor size (maximal diameter) } \\
\hline$<5 \mathrm{~cm}$ & $64(50.4)$ \\
\hline$\geq 5 \mathrm{~cm}$ & $63(49.6)$ \\
\hline \multicolumn{2}{|l|}{ pT } \\
\hline T1-2 & $41(32.3)$ \\
\hline T3-4 & $86(67.7)$ \\
\hline \multicolumn{2}{|l|}{$\mathrm{pN}$} \\
\hline No & $29(22.8)$ \\
\hline Yes & $98(77.2)$ \\
\hline \multicolumn{2}{|l|}{ TNM } \\
\hline $\mathrm{I} / \mathrm{II}$ & $39(30.7)$ \\
\hline III/IV & $88(69.3)$ \\
\hline \multicolumn{2}{|l|}{ Distant metastasis } \\
\hline No & $100(78.7)$ \\
\hline Yes & $27(21.3)$ \\
\hline \multicolumn{2}{|l|}{ Liver metastasis } \\
\hline No & $123(96.9)$ \\
\hline Yes & $4(3.1)$ \\
\hline \multicolumn{2}{|l|}{ Peritoneal seeding } \\
\hline No & $109(85.8)$ \\
\hline Yes & $18(14.2)$ \\
\hline \multicolumn{2}{|l|}{ Histological type } \\
\hline Well-differentiated & $4(3.1)$ \\
\hline Moderately-differentiated & $37(29.1)$ \\
\hline Poorly-differentiated & $86(67.8)$ \\
\hline
\end{tabular}

TNM, tumor-node-metastasis stage; $\mathrm{pT}$, depth of invasion; $\mathrm{pN}$, lymph node status.

and Snail $(\mathrm{P}<0.001)$ were significantly correlated with the OS rate (Table II; Fig. 2). Multivariate analysis revealed that high expression of CXCL1 ( $\mathrm{P}=0.011$; Table III) and Snail $(\mathrm{P}=0.013$; Table III) were independent prognostic factors for worse OS rates. The patients demonstrating increased expression of CXCL1 and Snail were revealed by univariate and multivariate analyses to possess worse prognoses compared with the other groups $(\mathrm{P}=0.001$ and $\mathrm{P}=0.005$, respectively; Tables II and III; Fig. 3).
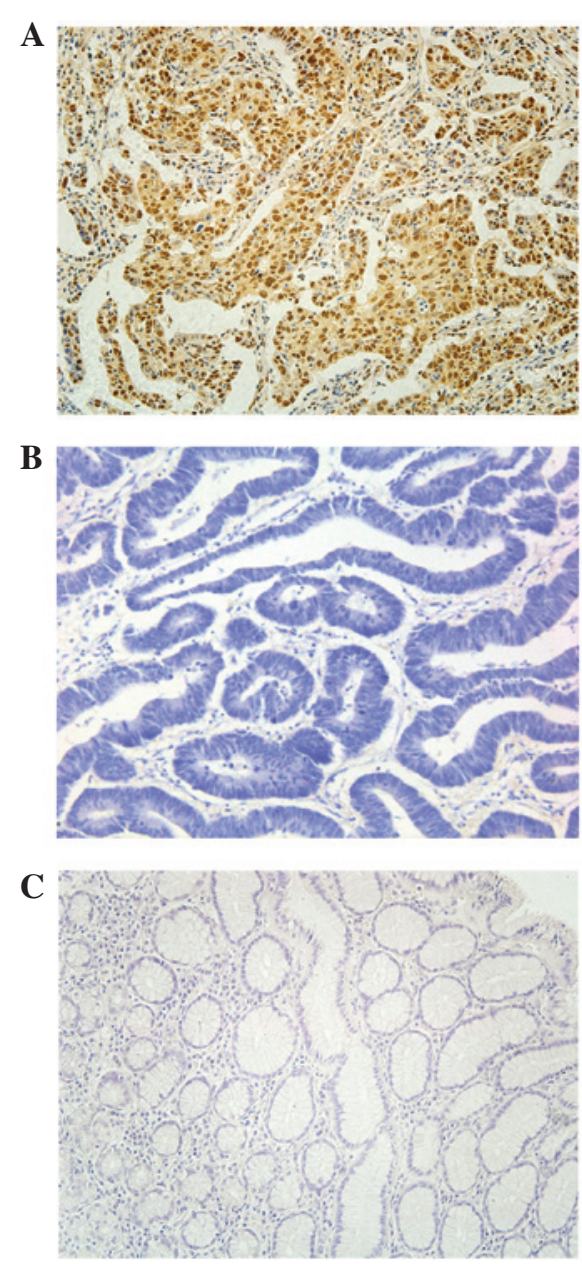

Figure 1. Expression of chemokine (C-X-C motif) ligand in gastric cancer and para-carcinoma tissues, as determined by immunohistochemistry. (A) CXCL1-positive and (B) CXCL1-negative tumor tissue; and (C) CXCL1-negative normal tissue (streptavidin-peroxidase method; magnification, $\mathrm{x} 200$ ).

Association between the expression levels of CXCL1 and Snail and the clinical characteristics of patients. The association between the expression of CXCL1 and Snail and the clinical characteristics of the 127 patients with GC is illustrated in Table VI. The expression levels of CXCL1 and Snail were each significantly associated with tumor size $(\mathrm{P}=0.013$ and $\mathrm{P}=0.026$, respectively), depth of invasion $(\mathrm{P}=0.003$ and $\mathrm{P}=0.001$, respectively), lymph node metastasis $(\mathrm{P}=0.022$ and $\mathrm{P}=0.014$, respectively) and $\mathrm{TNM}$ staging $(\mathrm{P}=0.001$ and $\mathrm{P}=0.005$, respectively). The overexpression of Snail was also associated with peritoneal seeding $(\mathrm{P}=0.009)$.

Correlation between CXCL1 and Snail overexpression. The association between CXCL1 and Snail expression was evaluated using Spearman's rank correlation and Fisher's exact test. The results revealed that there was a significantly positive correlation between the expression levels of CXCL1 and Snail in $\mathrm{GC}$ tissue ( $\mathrm{r}=0.431, \mathrm{P}<0.001$; Fig. 5).

\section{Discussion}

In the present study, CXCL1 and Snail were found to frequently be overexpressed in GC tissues, and the overexpression was 
Table II. Univariate analysis of factors associated with the overall survival rate.

\begin{tabular}{|c|c|c|c|}
\hline \multirow[b]{2}{*}{ Variables } & \multicolumn{2}{|c|}{ Overall survival } & \multirow[b]{2}{*}{ P-value } \\
\hline & HR & $95 \% \mathrm{CI}$ & \\
\hline \multicolumn{4}{|l|}{ Age } \\
\hline$<60$ years vs. $\geq 60$ years & 0.885 & $0.554-1.414$ & 0.610 \\
\hline \multicolumn{4}{|l|}{ Gender } \\
\hline Male vs. female & 1.120 & $0.663-1.893$ & 0.671 \\
\hline \multicolumn{4}{|l|}{ Tumor size } \\
\hline$<5 \mathrm{~cm}$ vs. $\geq 5 \mathrm{~cm}$ & 0.426 & $0.263-0.689$ & 0.000 \\
\hline \multicolumn{4}{|l|}{ T classification } \\
\hline T1-2 vs. T3-4 & 0.235 & $0.126-0.440$ & 0.000 \\
\hline \multicolumn{4}{|l|}{ TNM } \\
\hline I/II vs. III/IV & 0.179 & $0.088-0.362$ & 0.000 \\
\hline \multicolumn{4}{|l|}{ Lymph node status } \\
\hline Yes vs. no & 0.194 & $0.084-0.448$ & 0.000 \\
\hline \multicolumn{4}{|l|}{ Distant metastasis } \\
\hline Yes vs. no & 0.189 & $0.111-0.324$ & 0.000 \\
\hline \multicolumn{4}{|l|}{ Peritoneal seeding } \\
\hline Yes vs. no & 0.352 & $0.195-0.635$ & 0.001 \\
\hline \multicolumn{4}{|l|}{ Snail expression } \\
\hline High vs. low & 0.403 & $0.251-0.646$ & 0.000 \\
\hline \multicolumn{4}{|l|}{ CXCL1 expression } \\
\hline High vs. low & 0.371 & $0.215-0.641$ & 0.000 \\
\hline
\end{tabular}

Table III. Multivariate analysis of CXCL1 expression associated with the overall survival rate.

\begin{tabular}{lccc}
\hline & \multicolumn{2}{c}{ Overall survival } & \\
\cline { 2 - 3 } & HR & $95 \%$ CI & P-value \\
Variables & & & \\
\hline $\begin{array}{l}\text { Age } \\
\quad 60 \text { years vs. } \geq 60 \text { years }\end{array}$ & 0.863 & $0.519-1.433$ & 0.569 \\
$\begin{array}{l}\text { Gender } \\
\text { Male vs. female }\end{array}$ & 1.208 & $0.692-2.110$ & 0.506 \\
$\begin{array}{l}\text { T classification } \\
\text { T1-2 vs. T3-4 }\end{array}$ & 0.518 & $0.261-1.027$ & 0.060 \\
$\begin{array}{l}\text { Lymph node status } \\
\text { Yes vs. no }\end{array}$ & 0.267 & $0.102-0.701$ & 0.007 \\
$\begin{array}{l}\text { Distant metastasis } \\
\text { Yes vs. no }\end{array}$ & 0.255 & $0.137-0.476$ & 0.000 \\
$\begin{array}{l}\text { Peritoneal seeding } \\
\text { Yes vs. no }\end{array}$ & 0.718 & $0.366-1.406$ & 0.334 \\
$\begin{array}{l}\text { Differention } \\
\text { Well/moderately vs. poorly }\end{array}$ & 1.045 & $0.579-1.887$ & 0.884 \\
$\begin{array}{l}\text { CXCL1 expression } \\
\text { High vs. low }\end{array}$ & 0.473 & $0.266-0.842$ & 0.011 \\
$\begin{array}{l}\text { HR, hazard ratio; CI, confidence interval; T classification, depth of } \\
\text { tumor invasion; CXCL1, chemokine (C-X-C motif) ligand. }\end{array}$ & \\
\hline
\end{tabular}

Table IV. Multivariate analysis of Snail expression associated with the overall survival rate.

\begin{tabular}{lccc}
\hline & \multicolumn{2}{c}{ Overall survival } & \\
\cline { 2 - 3 } & HR & $95 \%$ CI & P-value \\
Variables & & & \\
\hline $\begin{array}{l}\text { Age } \\
\quad 60 \text { years vs. } \geq 60 \text { years }\end{array}$ & 0.823 & $0.507-1.366$ & 0.467 \\
$\begin{array}{l}\text { Gender } \\
\text { Male vs. female }\end{array}$ & 1.087 & $0.617-1.916$ & 0.772 \\
$\begin{array}{l}\text { T Classification } \\
\text { T1-2 vs. T3-4 }\end{array}$ & 0.519 & $0.264-1.023$ & 0.058 \\
$\begin{array}{l}\text { Lymph node status } \\
\text { Yes vs. no }\end{array}$ & 0.234 & $0.090-0.610$ & 0.003 \\
$\begin{array}{l}\text { Distant metastasis } \\
\text { Yes vs. no }\end{array}$ & 0.279 & $0.149-0.521$ & 0.000 \\
$\begin{array}{l}\text { Peritoneal seeding } \\
\text { Yes vs. no }\end{array}$ & & & \\
$\begin{array}{l}\text { Differention } \\
\text { Well/moderately vs. poorly }\end{array}$ & 1.028 & $0.574-1.853$ & 0.926 \\
$\begin{array}{l}\text { Snail expression } \\
\text { High vs. low }\end{array}$ & 0.515 & $0.306-0.867$ & 0.013 \\
\hline
\end{tabular}

$\mathrm{HR}$, hazard ratio; CI, confidence interval.

Table V. Multivariate analysis of CXCL1 and Snail expression associated with the overall survival rate.

\begin{tabular}{lccc}
\hline & \multicolumn{2}{c}{ Overall survival } & \\
\cline { 2 - 3 } & HR & $95 \%$ CI & P-value \\
Variables & & & \\
\hline $\begin{array}{l}\text { Age } \\
\quad 60 \text { years vs. } \geq 60 \text { years }\end{array}$ & 0.831 & $0.504-1.370$ & 0.469 \\
$\begin{array}{l}\text { Gender } \\
\quad \text { Male vs. female }\end{array}$ & 1.157 & $0.663-2.022$ & 0.608 \\
$\begin{array}{l}\text { T Classification } \\
\text { T1-2 vs. T3-4 }\end{array}$ & 0.512 & $0.260-1.005$ & 0.052 \\
$\begin{array}{l}\text { Lymph node status } \\
\quad \text { Yes vs. no }\end{array}$ & 0.253 & $0.097-0.659$ & 0.005 \\
$\begin{array}{l}\text { Distant metastasis } \\
\quad \text { Yes vs. no }\end{array}$ & 0.242 & $0.129-0.455$ & 0.000 \\
$\begin{array}{l}\text { Peritoneal seeding } \\
\text { Yes vs. no }\end{array}$ & 0.709 & $0.361-1.393$ & 0.318 \\
$\begin{array}{l}\text { Differention } \\
\text { Well/moderately vs. poorly }\end{array}$ & 1.020 & $0.566-1.839$ & 0.946 \\
$\begin{array}{l}\text { CXCL1 and Snail expression } \\
\text { CXCL1-/Snail- vs. others }\end{array}$ & 0.395 & $0.208-0.751$ & 0.005 \\
\hline
\end{tabular}

HR, hazard ratio; CI, confidence interval; $\mathrm{T}$ classification, depth of tumor invasion; CXCL1, chemokine (C-X-C motif) ligand.

associated with a worse prognosis. Patients with combined CXCL1 and Snail overexpression exhibited a significantly worse prognosis compared to patients with either CXCL1 or 
Table VI. Association between CXCL1 and Snail expression levels and clinical characteristics of patients with gastric cancer.

\begin{tabular}{|c|c|c|c|c|c|c|}
\hline \multirow[b]{2}{*}{ Characteristics } & \multicolumn{2}{|c|}{ CXCL1 expression } & \multirow[b]{2}{*}{ P-value } & \multicolumn{2}{|c|}{ Snail expression } & \multirow[b]{2}{*}{ P-value } \\
\hline & Present & Absent & & Present & Absent & \\
\hline \multicolumn{7}{|l|}{ Age } \\
\hline$<60$ years & 43 & 34 & 0.067 & 34 & 43 & 0.986 \\
\hline$\geq 60$ years & 36 & 14 & & 22 & 28 & \\
\hline \multicolumn{7}{|l|}{ Gender } \\
\hline Male & 56 & 36 & 0.614 & 44 & 48 & 0.170 \\
\hline Female & 23 & 12 & & 12 & 23 & \\
\hline \multicolumn{7}{|l|}{ Location } \\
\hline Upper third & 18 & 24 & 0.513 & 17 & 25 & 0.309 \\
\hline Middle third & 11 & 17 & & 16 & 12 & \\
\hline Lower third & 17 & 29 & & 17 & 29 & \\
\hline Whole & 2 & 9 & & 6 & 5 & \\
\hline \multicolumn{7}{|c|}{ Maximal tumor diameter } \\
\hline$<5 \mathrm{~cm}$ & 31 & 33 & 0.013 & 22 & 42 & 0.026 \\
\hline$\geq 5 \mathrm{~cm}$ & 17 & 46 & & 34 & 29 & \\
\hline \multicolumn{7}{|l|}{$\mathrm{pT}$} \\
\hline $\mathrm{T} 1-2$ & 18 & 23 & 0.003 & 9 & 32 & 0.001 \\
\hline T3-4 & 61 & 25 & & 47 & 39 & \\
\hline \multicolumn{7}{|l|}{$\mathrm{pN}$} \\
\hline N0+N1 & 47 & 38 & 0.022 & 31 & 54 & 0.014 \\
\hline $\mathrm{N} 2+\mathrm{N} 3$ & 32 & 10 & & 25 & 17 & \\
\hline \multicolumn{7}{|l|}{ TNM staging } \\
\hline $\mathrm{I} / \mathrm{II}$ & 16 & 23 & 0.001 & 29 & 10 & 0.005 \\
\hline III/IV & 63 & 25 & & 42 & 46 & \\
\hline \multicolumn{7}{|c|}{ Distant metastasis } \\
\hline Negative & 39 & 61 & 0.590 & 41 & 59 & 0.091 \\
\hline Positive & 9 & 18 & & 16 & 11 & \\
\hline \multicolumn{7}{|c|}{ Peritoneal seeding } \\
\hline Negative & 66 & 43 & 0.344 & 43 & 66 & 0.009 \\
\hline Positive & 13 & 5 & & 13 & 5 & \\
\hline \multicolumn{7}{|l|}{ Histology type } \\
\hline Well & 2 & 2 & 0.597 & 3 & 1 & 0.443 \\
\hline Moderately & 21 & 16 & & 23 & 14 & \\
\hline Poorly & 56 & 30 & & 45 & 41 & \\
\hline
\end{tabular}

pT, depth of invasion; pN, lymph node status.

Snail overexpression alone or decreased expression of these proteins. Correlation analysis revealed that CXCL1 expression was significantly associated with Snail expression in GC tissue. These results demonstrated that CXCL1 and Snail expression may act as a prognostic biomarker in GC, and CXCL1 may promote tumor metastasis by regulating EMT through Snail.

CXCL1-mediated melanocyte transformation is involved in the induction of Ras expression, and RAS-induced CXCL1 facilitates the transformation of human ovarian epithelial cell $(4,18)$. The present data revealed that CXCL1 was highly expressed in GC (62.2\%) and may be critical to tumorigenesis and tumor metastasis. CXCL1 was highly expressed in breast cancer metastases and CXCL1 regulated the expression of matrix metalloproteinase (MMP)-13 and promoted the invasion of the tumor into the bladder $(19,20)$. CXCL1 also mediated the metastasis of squamous cell carcinoma (21). In GC, CXCL1/CXCR2 upregulates MMP2, MMP9, N-Ras, K-Ras, signal transducer and activator of transcription 3 and promote the migratory and invasive abilities of tumor cells (8). The results of the present analysis revealed that high expression of CXCL1 is associated with tumor invasion and tumor metastasis and may act as an independent prognosis biomarker in GC. Subsequently, Snail expression was detected by IHC and the association between Snail and the prognosis of patients with GC and clinicopathological characteristics 

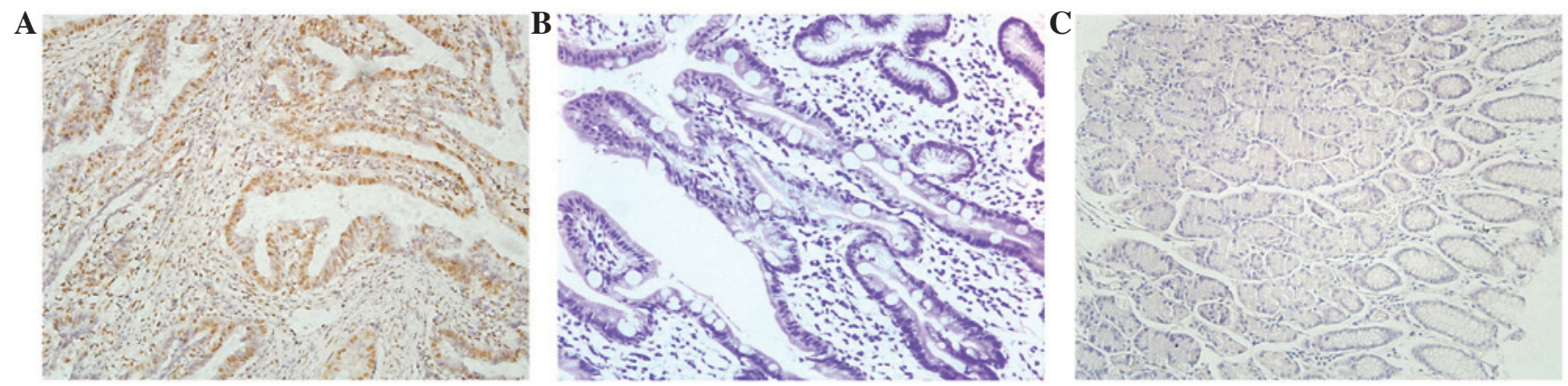

Figure 2. Expression of Snail in gastric cancer and para-carcinoma tissues, as determined by immunohistochemistry. (A) Snail positive and (B) negative tumor tissue; and (C) Snail negative normal tissue (streptavidin-peroxidase method; magnification, x200).

A

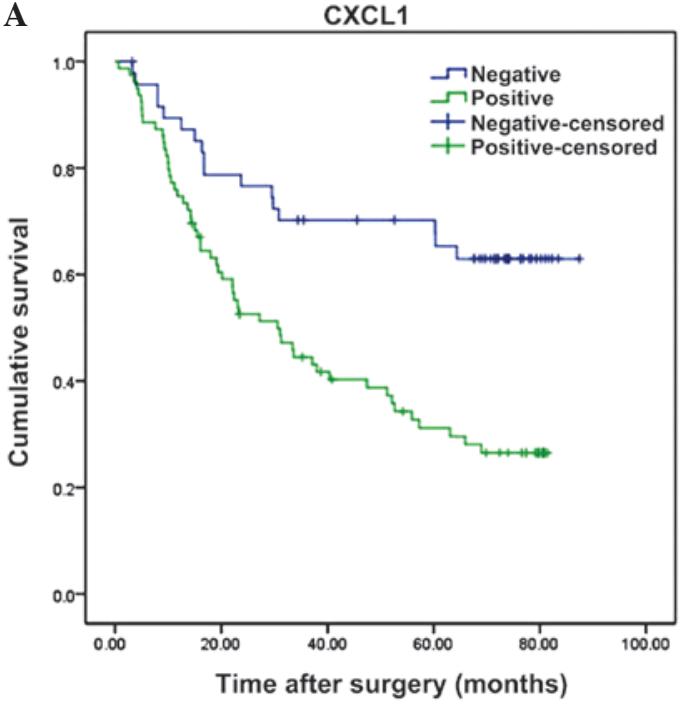

B

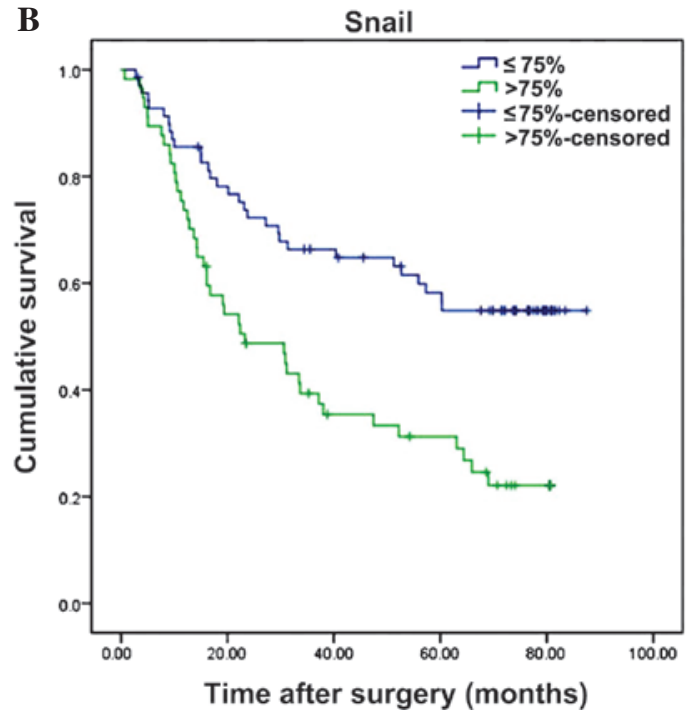

Figure 3. Kaplan-Meier analysis of the overall survival time of patients with gastric cancer, based on CXCL1 and Snail expression. (A) High CXCL1 expression in gastric cancer tissue was associated with a poor overall survival time $(\mathrm{P}<0.001)$. (B) High Snail expression was also associated with a worse overall survival time $(\mathrm{P}<0.001)$. CXCL1, chemokine ( $\mathrm{C}-\mathrm{X}-\mathrm{C}$ motif) ligand.

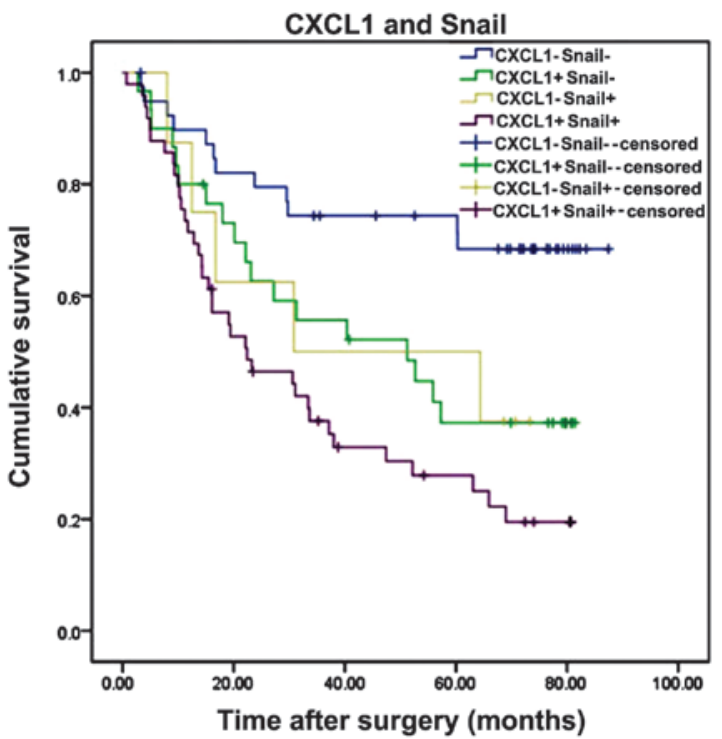

Figure 4. Kaplan-Meier analysis of the overall survival time for patients with gastric cancer, based on CXCL1 and Snail expression. CXCL1 and Snail expression in primary lesions was divided into four groups, consisting of the CXCL1 ${ }^{-} /$Snail ${ }^{-}(\mathrm{n}=40), \mathrm{CXCL1}^{+} / \mathrm{Snail}^{-}(\mathrm{n}=30), \mathrm{CXCL1}^{-} / \mathrm{Snail}{ }^{+}(\mathrm{n}=8)$ and $\mathrm{CXCL1}^{+} / \mathrm{Snail}^{+}(\mathrm{n}=49)$ groups. The overall survival time in patients in the $\mathrm{CXCLI}^{+} / \mathrm{Snail}^{+}$group was significantly lower compared with the OS time in the other three groups $(\mathrm{P}=0.001)$. CXCL1, chemokine ( $\mathrm{C}-\mathrm{X}-\mathrm{C}$ motif) ligand.

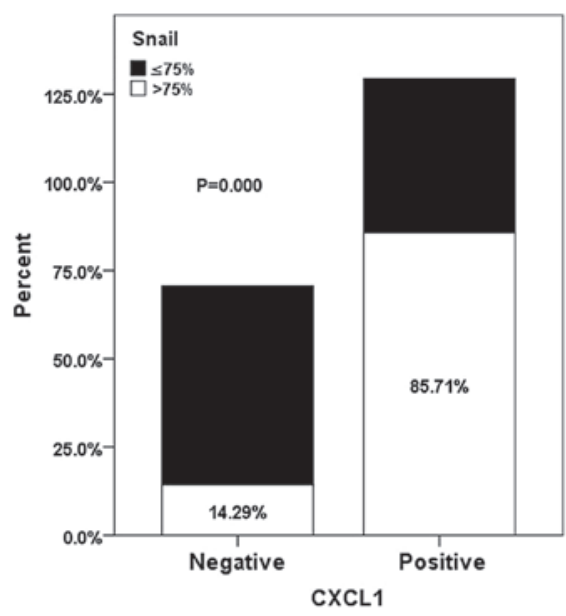

Figure 5. Association between Snail expression and CXCL1 expression, determined using Fisher's exact test. CXCL1, chemokine (C-X-C motif) ligand.

was analyzed. The results indicated that Snail was associated with a worse prognosis and clinicopathological characteristics. Snail-mediated downregulation of E-cadherin expression has been reported to perform a critical role in tumor invasion and 
metastasis, including in hepatocellular carcinoma and breast cancer $(22,23)$. In GC, NF- $\kappa$ B activation increases Snail expression. Snail then downregulates E-cadherin expression and promotes EMT. Finally, the activation of EMT leads to tumor metastasis (12-14,24). Analysis of the prognosis of patients with combined CXCL1 and Snail expression, the $\mathrm{CXCL1}^{+} / \mathrm{Snail}^{+}$group exhibited a worse prognosis compared with the other groups, particularly the $\mathrm{CXCL1}^{-} / \mathrm{Snail}^{-}$group. Furthermore, the difference between the $\mathrm{CXCL1}^{+} / \mathrm{Snail}^{+}$and $\mathrm{CXCL1}^{-/}$Snail ${ }^{-}$groups was more significant compared with that of the CXCL1 ${ }^{+}$or Snail ${ }^{+}$groups.

Finally, Spearman's rank correlation and Fisher's exact test were performed to analyze the association between CXCL1 expression and Snail expression. Notably, the expression of Snail was significantly associated with the expression of CXCL1. CXCL1 combines with CXCR2 and may regulate cellular apoptosis through NF- $\mathrm{KB}$ in ovarian cancer (25). Augmentation of the proinflammatory chemokine CXCL1 may also activate NF- $\mathrm{BB}$ and promote tumor cell migration and invasion, such as in ovarian and prostate cancer $(6,7)$. As aforementioned, NF- $\kappa \mathrm{B}$ activation may upregulate Snail and Snail overexpression results in EMT and leads to tumor metastasis. Therefore, CXCL1 may upregulate Snail in GC. In order to further clarify the association between CXCL1 and Snail, the GC AGS cell line was stimulated by CXCL1 (48 h) and western blot was performed to detect Snail expression. As a result, Snail was upregulated (data not shown). Thus, CXCL1 may bind to CXCR2, activate NF-kB and upregulate Snail. The upregulation of Snail downregulates E-cadherin and promotes EMT, leading to tumor invasion and metastasis. However, additional studies are required to explore this hypothesis.

The present results demonstrated that CXCL1 and Snail are highly expressed in GC and are associated with tumor progression and a worse prognosis. The combined expression of CXCL1 and Snail may be more effective to predict the prognosis of patients with GC, and the expression of Snail and CXCL1 are positively correlated with each other. Therefore, additional studies are required to confirm whether CXCL1 may upregulate Snail expression and lead to tumor progression and clarify the underlying mechanisms.

\section{Acknowledgements}

This study was supported by the National Nature Science Research Fund of China (grant nos. 30700805 and 81272643).

\section{References}

1. Jemal A, Bray F, Center MM, Ferlay J, Ward E and Forman D: Global cancer statistics. CA Cancer J Clin 61: 69-90, 2011.

2. Okholm C, Svendsen LB and Achiam MP: Status and prognosis of lymph node metastasis in patients with cardia cancer-A systematic review. Surg Oncol 23: 140-146, 2014.

3. Deng JY and Liang H: Clinical significance of lymph node metastasis in gastric cancer. World J Gastroenterol 20: 3967-3975, 2014.

4. Wang D, Yang W, Du J, Devalaraja MN, Liang P, Matsumoto K, Tsubakimoto K, Endo T and Richmond A: MGSA/GRO-mediated melanocyte transformation involves induction of Ras expression. Oncogene 19: 4647-4659, 2000.

5. Dhawan P and Richmond A: Role of CXCL1 in tumorigenesis of melanoma. J Leukoc Biol 72: 9-18, 2002.
6. Dong YL, Kabir SM, Lee ES and Son DS: CXCR2-driven ovarian cancer progression involves upregulation of proinflammatory chemokines by potentiating NF- $\kappa \mathrm{B}$ activation via EGFR-transactivated Akt signaling. PLoS One 8: e83789, 2013.

7. Kuo PL, Shen KH,Hung SH and Hsu YL:CXCL1/GRO $\alpha$ increases cell migration and invasion of prostate cancer by decreasing fibulin-1 expression through NF- $\mathrm{B} / \mathrm{HDAC} 1$ epigenetic regulation. Carcinogenesis 33: 2477-2487, 2012.

8. Cheng WL, Wang CS, Huang YH, et al: Overexpression of CXCL1 and its receptor CXCR2 promote tumor invasion in gastric cancer. Ann Oncol 22: 2267-2276, 2011.

9. Thompson EW, Newgreen DF and Tarin D: Carcinoma invasion and metastasis: A role for epithelial-mesenchymal transition? Cancer Res 65: 5991-5995, discussion 5995, 2005.

10. Shin NR, Jeong EH, Choi CI, et al: Overexpression of Snail is associated with lymph node metastasis and poor prognosis in patients with gastric cancer. BMC Cancer 12: 521, 2012.

11. He H, Chen W, Wang X, et al: Snail is an independent prognostic predictor for progression and patient survival of gastric cancer. Cancer Sci 103: 1296-1303, 2012.

12. Cho HJ, Park SM, Kim IK, et al: RhoGDI2 promotes epithelial-mesenchymal transition via induction of Snail in gastric cancer cells. Oncotarget 5: 1554-1564, 2014.

13. Chen Z, Liu M, Liu X, et al: COX-2 regulates E-cadherin expression through the NF- $\mathrm{kB} /$ Snail signaling pathway in gastric cancer. Int J Mol Med 32: 93-100, 2013.

14. Zheng H, Li W, Wang Y, et al: Glycogen synthase kinase-3 beta regulates Snail and $\beta$-catenin expression during Fas-induced epithelial-mesenchymal transition in gastrointestinal cancer. Eur J Cancer 49: 2734-2746, 2013.

15. Washington K: 7th edition of the AJCC cancer staging manual: Stomach. Ann Surg Oncol 17: 3077-3079, 2010.

16. Ding T, Xu J, Wang F, et al: High tumor-infiltrating macrophage density predicts poor prognosis in patients with primary hepatocellular carcinoma after resection. Hum Pathol 40: 381-389, 2009.

17. Goulding H, Pinder S, Cannon P, et al: A new immunohistochemical antibody for the assessment of estrogen receptor status on routine formalin-fixed tissue samples. Hum Pathol 26: 291-294, 1995.

18. Yang G, Rosen DG, Zhang Z, et al: The chemokine growth-regulated oncogene 1 (Gro-1) links RAS signaling to the senescence of stromal fibroblasts and ovarian tumorigenesis. Proc Natl Acad Sci U S A 103: 16472-16477, 2006.

19. Kawanishi H, Matsui Y, Ito M, et al: Secreted CXCL1 is a potential mediator and marker of the tumor invasion of bladder cancer. Clin Cancer Res 14: 2579-2587, 2008.

20. Lerebours F, Vacher S, Andrieu C, et al: NF-kappa B genes have a major role in inflammatory breast cancer. BMC Cancer 8: 41, 2008.

21. Loukinova E, Dong G, Enamorado-Ayalya I, et al: Growth regulated oncogene-alpha expression by murine squamous cell carcinoma promotes tumor growth, metastasis, leukocyte infiltration and angiogenesis by a host CXC receptor-2 dependent mechanism. Oncogene 19: 3477-3486, 2000.

22. Zhou L, Wang DS, Li QJ, Sun W, Zhang Y and Dou KF: The down-regulation of Notch1 inhibits the invasion and migration of hepatocellular carcinoma cells by inactivating the cyclooxygenase-2/Snail/E-cadherin pathway in vitro. Dig Dis Sci 58: 1016-1025, 2013.

23. Dong CF, Wu Y, Yao J, et al: G9a interacts with Snail and is critical for Snail-mediated E-cadherin repression in human breast cancer. J Clin Invest 122: 1469-1486, 2012.

24. Yoo YA, Kang MH, Lee HJ, et al: Sonic hedgehog pathway promotes metastasis and lymphangiogenesis via activation of Akt, EMT and MMP-9 pathway in gastric cancer. Cancer Res 71: 7061-7070, 2011.

25. Yang G, Rosen DG, Liu GZ, et al: CXCR2 promotes ovarian cancer growth through dysregulated cell cycle, diminished apoptosis and enhanced angiogenesis. Clin Cancer Res 16: 3875-3886, 2010. 